\title{
Editorial: Medical Education during the COVID-19 Pandemic; An insight
}

Divya $\mathbf{R}^{1}$, Selvakumar $S^{2}$

${ }^{1}$ Associate professor, Department of Physiology, Dhanalakshmi Srinivasan Medical college and Hospital, Perambalur, Tamilnadu, India.

${ }^{2}$ Assistant professor, Department of Physiology, Dhanalakshmi Srinivasan Medical college and Hospital, Perambalur, Tamilnadu, India.

*Corresponding Author: Divya R, Associate professor, Department of Physiology, Dhanalakshmi Srinivasan Medical College and Hospital, Perambalur, Tamilnadu, India.

Received date: April 01, 2021: Accepted date: April 03, 2021: Published date: April 30,2021

Citation: Divya R*, Selvakumar S (2021) Medical Education during the COVID-19 Pandemic; An insight J. of Clin Case Rep and Stu 2(2); DOI: 10.31579/2690-8808/072

Copyright: () 2021: Divya R. This is an open access article distributed under the Creative Commons Attribution License, which permits unrestricted use, distribution, and reproduction in any medium, provided the original work is properly cited.

\section{Introduction:}

The Coronavirus Disease 2019 has produced weighty hindrances for the medical educators' delivery of healthcare and medical education. The educational strategies besieging the pandemic aid inimitable challenges to the medical students interested in pursuing Medicine [1].

Many Medical schools have cancelled the classes for Students for various concerns such as to flatten the curve, curtail personal interfaces, comprehend the spread and to cutback the risk of exposure for medical students [2].

The instantaneous effect of the novel coronavirus (COVID-19) pandemic is the cancellation of in-person medical classes. The one-to-one lectures were replaced by recorded lectures or online live-streaming classes [2].

\section{Conclusion:}

In face of COVID-19 pandemic and its novel challenges, the medical educators need to think outside the box and amend their vistas to pander in various pioneering slants to address the practical difficulties associated with the state of affairs. In this unique circumstances, medical students should pilot the challenges with Perseverance and compliance. Instigating technology into medical education will help in stamping out the preconceived notions of how medicine should be taught.

\section{References:}

1. Guadix SW, Winston GM, Chae JK, et al. (2020) Medical Student Concerns Relating to Neurosurgery Education During COVID19. World Neurosurg. S1878-8750(20)31061-5. doi:10.1016/j.wneu.2020.05.090.

2. Ferrel MN, Ryan JJ. (2020) The Impact of COVID-19 on Medical Education. Cureus; 12(3):e7492. doi:10.7759/cureus.7492 